Косторный Игорь Юрьевич, Лепяхова Елена Николаевна

\title{
МЕРЫ ПОВЫШЕНИЯ ЭФФЕКТИВНОСТИ ПРОИЗВОДСТВА СЕЛЬСКОХОЗЯЙСТВЕННЫХ КУЛЬТУР НА ПРИМЕРЕ СПК КОЛХОЗА-ПЛЕМЗАВОДА «КАЗЬМИНСКИЙ»
}

Цель статьи заключается в рассмотрении эффективности производства зерновьгх культур в СПК колхозе-племзаводе «Казьминский». Составлена аналитическая таблица, раскрывающая основные экономические показатели, влияюцие на эффективность производства зерна. Проведён качествениый анализ показателей; определены три ключевых фактора, влияюиих на эффективность, а именно: агробиологические, технико-технологическе, организационно-экономические. Предложены реальные соответствуюиие мероприятия для нивелирования влияния каждого из факторов с конкретными примерами внедрения. В заключение рассчитана эффективность от внедрения каждого из мероприятий. экономика.

Ключевые слова: Зерновые культуры, эффективность, производство, сельское хозяйство,

\section{Igor Kostornyy, Elena Lepyakhova \\ MEASURES TO IMPROVE THE EFFICIENCY OF THE PRODUCTION OF AGRICULTURAL CULTURES ON THE EXAMPLE OF THE SECK KOLKHOZ-PLEMING PLANT «KAZMINSKIY»}

The purpose of the article is to review the efficiency of production of grain crops in the SEC collective farm-breeding plant "Kazminsky". An analytical table was compiled, revealing the main economic indicators affecting the efficiency of grain production. A qualitative analysis of indicators. Identified three key factors affecting the efficiency, namely, agrobiological, technical, technological, organizational and economic. Real and appropriate measures are proposed for leveling the influence of each of the factors, with specific examples of implementation. In conclusion, the calculated effectiveness of the implementation of each of the activities.

Key words: Grain crops, efficiency, production, agriculture, economy.

Bведение / Introduction. В настоящее время перед сельским хозяйством стоит проблема обеспечения населения продовольствием и сохранение внутреннего продовольственного рынка, представленного отечественными товаропроизводителями, так как именно это обеспечит продовольственную безопасность страны. Главной задачей для роста всех отраслей сельского хозяйства является наращивание объёмов и качества производства зерновых культур.

Руководитель организации заинтересован в поиске новых путей развития и повышения эффективности, объёмов производства и реализации продукции, так как именно это будет способствовать увеличению прибыли организации и рентабельности деятельности. На сегодняшний момент можно выделить три основные группы факторов, влияющих на производство сельскохозяйственных культур:

- агробиологические;

- технико-технологические;

- организационно-экономические.

Mameриалы и методы / Materials and methods. В работе были применены такие методы, как горизонтальный анализ, вертикальный анализ, метод сравнения и группировки, а также балансовый метод. 
СПК колхоз-племзавод «Казьминский» является одним из ведущих сельскохозяйственных предприятий в Ставропольском крае, да и в России. Расположен в 30 километрах на юго-запад от города Невинномысска в Ставропольском крае. Численность работников СПК колхоз-племзавод «Казьминский» составляет 1500 человек.

Хозяйство в настоящее время имеет зерно- и скотоводческое направление, но основным видом деятельности колхоза является растениеводство - производство зерна. Зерновые культуры представлены большим разнообразием, несмотря на свои индивидуальные агробиологические особенности, все они могут быть проанализированы по унифицированной системе показателей.

От эффективности показателей деятельности системы реализации, производства зерна зависят ключевые показатели деятельности. Динамику основных показателей производства зерна в СПК колхоз-племзавод «Казьминский», можно проследить по данным таблицы (таблица 1)

Таблица 1

Показатели эффективности производства зерна в СПК колхоз-племзавод «Казьминский»

\begin{tabular}{|l|c|c|c|c|}
\hline \multicolumn{1}{|c|}{ Показатели } & $\mathbf{2 0 1 5}$ г. & $\mathbf{2 0 1 6}$ г. & $\mathbf{2 0 1 7}$ г. & $\begin{array}{c}\text { Aбсолютное } \\
\text { изенение } \\
\text { (+, -) }\end{array}$ \\
\hline Посевная площадь, га & 15150 & 15193 & 15100 & -50 \\
\hline Урожайность, ц/га & 79 & 77 & 75 & -4 \\
\hline Валовой сбор, ц & 1193314 & 1172722 & 1134066 & -59248 \\
\hline Реализовано продукцин, ц & 968012 & 915590 & 1174130 & 206118 \\
\hline Уровень товарности, \% & 81 & 78 & 103 & 22 \\
\hline Полная себестонмость, тыс. руб. & 547105 & 615217 & 819329 & 272224 \\
\hline Выручка от реализации, тыс. руб. & 935155 & 952074 & 1035362 & 100207 \\
\hline Прибыль на 1 ц, руб. & 400 & 367 & 247 & -153 \\
\hline Средняя цена реализации продукции, руб. & 966 & 1040 & 881 & -85 \\
\hline Средняя себестоимость 1 ц продукции, руб. & 560 & 671 & 648 & 88 \\
\hline Рентабельность продаж, \% & 41 & 35 & 26 & -15 \\
\hline Площадь пашни на 1 трактор, га & 102 & 110 & 103 & 1 \\
\hline Площадь посевов на 1 комбайн, га & 202 & 166 & 173 & -29 \\
\hline Ресурсоёмкость, руб. & 0,52 & 0,61 & 0,65 & 0,13 \\
\hline
\end{tabular}

За период исследования показатель ресурсоёмкости возрос на 0,13 пункта. Такая динамика свидетельствует о неэффективном использовании имеющихся технологий и о росте затрат на производство. Также снизилась урожайность зерновых культур на 4 центнера с га.

Возрос уровень товарности, что говорит об увеличении запасов зерна. При этом значительно сократилась прибыль на 1 центнер зерна, всё это привело к общему падению рентабельности продаж на $15 \%$.

В исследуемом периоде эффективность производства зерновых культур в СПК колхозе-племзаводе «Казьминский» имела тенденцию снижения. Такая ситуация связана с сокращением урожайности культур, ростом себестоимости производства и одновременным снижением рыночных цен реализации (рис.).

Анализируя цены реализации пшеницы 3 класса в России, можно отследить динамику: в 2017 году средняя цена за 1 т в Северо-Кавказском регионе составляла 10400 руб., при этом СПК колхоз-племзавод «Казьминский» продавал её по 8940 руб. за т, что на 14 \% меньше. Аналогичная ситуация была и в 2016 году: цена на пшеницу составляла 11000 руб., а цена, по которой реализовал пшеницу СПК колхоз-племзавод «Казьминский», - 10790 руб., что на 3 \% меньше 


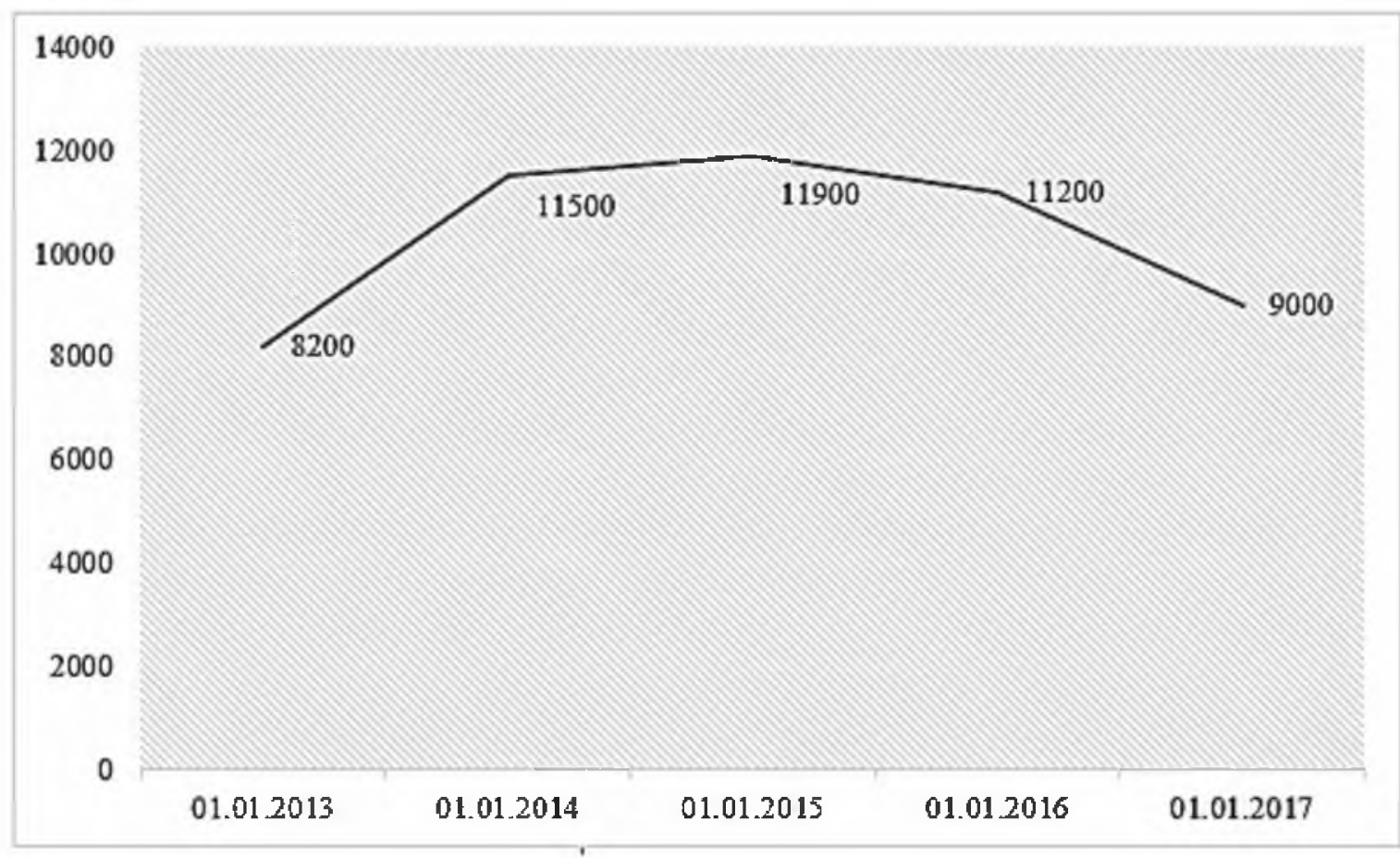

Рис. Динамика цены пшеницы за 5 последних лет

Такие неблагоприятные тенденции в сфере производства зерновых культур в СПК колхозе-племзаводе «Казьминский» говорят о необходимости применения мер по её повышению, для улучшения качества работы предприятия и роста финансовых результатов.

Peзультаты и обсуждение / Results and discussion. В рамках мероприятий, связанных с агробиологическими факторами влияния, следует применять новые, высокоэффективные удобрения.. Необходимо внедрить суспензию «Вуксал Микроплант», производимую российской компанией $\mathrm{OOO}$ «Апис», она должна стать заменой уже имеющейся суспензии «Florenta», производимой компанией ООО «Тараще».

Данное удобрение корректирует острый дефицит микроэлементов и предотвращает проявление скрытых дефицитов, что приводит к увеличению продуктивности культур. Данная суспензия предназначена для внекорневого внесения. Соотношение элементов питания отвечает физиологическим потребностям интенсивных культур, растения обеспечиваются наиболее необходимыми питательными элементами.

Таблица 2

Характеристики суспензий применяемых в СПК колхозе-племзаводе «Казьминском»

\begin{tabular}{|l|c|c|}
\hline \multicolumn{1}{|c|}{ Показатель } & $\begin{array}{c}\text { Исходные данные } \\
\text { суспензии «Florenta» }\end{array}$ & $\begin{array}{c}\text { Исходные данные суспензии } \\
\text { «Вуксал Микропллант» }\end{array}$ \\
\hline Расход, л/га & 8 & 4 \\
\hline Площадь посевов, га & 9500 & 9500 \\
\hline Необходимое количество, л & 76000 & 38000 \\
\hline Стоимость 1 литра, руб. & 300 & 700 \\
\hline Общие расходы, тыс. руб. & 22800 & 26600 \\
\hline Прирост урожайности, \% & 6 & 11 \\
\hline
\end{tabular}


Как предписывают нормы использования, применение суспензии предполагает её внесение по 1 литру на гектар, на 4 стадиях роста зерна. Её внедрение позволит организации увеличить урожайность на $15 \%$, при этом затраты на производство сократятся на $5 \%$ за счёт замены ряда минеральных удобрений на суспензию «Вуксал Микроплан». При условии, что вся собранная пшеница будет реализована, выручка возрастает на $15 \%$.

Таким образом, применение удобрений в виде суспензии позволит увеличить урожайность пшеницы и валовой сбор, что должно непосредственно отразиться на выручке.

В рамках мероприятий, связанных с нивелированием технико-технологических факторов влияния, предполагается замена парка комбайнов организации. На сегодняшний день автопарк в СПК колхозе-племзаводе «Казьминском〉 представлен в большей степени комбайнами марки Дон 1500-Б. Данный комбайн является устаревшим зерноуборочным комбайном от компании «Ростсельмаш», прекратившей их выпуск в 2006 году и заменившей их улучшенными моделями Vector, Acros и Torum.

Общее количество зерноуборочной техники в колхозе на конец 2017 года составило 65 единиц, из них, комбайны марки «Дон 1500-Б» - 35 единиц, остальные 30 единиц - это комбайны различных марок, включая Nova, Torum 750, John Deere, CK-5 Нива. Проводя анализ имеющейся техники, можно говорить о необходимости модернизации комбайнов для сокращения расходов на уборку, снижения потерь продукции, а также повышения валового сбора зерновых (таблица 3).

Таблица 3

Характеристика зерноуборочной техники в СПК колхозе-племзаводе «Кзьминском» в 2017 году

\begin{tabular}{|l|c|c|c|c|}
\hline \multicolumn{1}{|c|}{ Показатели } & Дон 1500-Б & Acros 550 & Torum 750 & $\begin{array}{c}\text { Отк.лонение } \\
(+/-)\end{array}$ \\
\hline Площадь посевов зерновых, га & \multicolumn{3}{|c|}{15100} & - \\
\hline Максимальная дневная площадь уборки, га & 20,0 & 30,0 & 40,0 & 20 \\
\hline Максимальный срок уборки зерновых, дней & 10,0 & 10,0 & 10,0 & - \\
\hline Необходимое количество машин, шт. & 76,0 & 50,0 & 38,0 & -38 \\
\hline Расход топлива, л на тонну зерна & $\mathbf{5 , 8}$ & 2,2 & 1,8 & -4 \\
\hline Производительность, т/ч & 14,0 & 30,0 & 39,0 & 25 \\
\hline Цена, тыс. руб. & 1400 & 7358 & 11990 & 10590 \\
\hline
\end{tabular}

Анализируя модель Torum 750 и Дон 1500-Б, можно заметить, что Torum имеет большую производительность труда, составляющую 39 т зерна за час уборки, что на 178 \% больше, чем у комбайна Дон 1500-Б, а также большую жатку, позволяющую увеличить площадь уборки с 20 гектар до 40 за один проход.

Замена комбайнов Дон 1500-Б на комбайны Torum 750 проходит в соотношении 2 к 1, при этом первоначально, по нашему мнению, рационально будет произвести замену 10 комбайнов Дон 1500-Б на 5 комбайнов Torum 750, общие инвестиции составят 46000 тыс. руб., при этом NPV проекта составит 1941843 тыс. руб.

После применения новых комбайнов урожайность зерновых возрастет на $10 \%$, при этом сократятся затраты на производство на $15 \%$. Такая тенденция отразится на общей выручке, которая также возрастет на $10 \%$.

Заключительным фактором, влияющим на производство зерна, являются организационно-экономические мероприятия. Они представляют собой комплекс мер по улучшению системы управления, снижению затрат и повышению результатов реализации продукции предприятия. В данную систему входят элементы операционного и стратегического планирования, контроллинга, менеджмента и маркетинга. 
Исходя из задач, решаемых системой контроллинга, для СПК колхоза-племзавода «Казьминский〉 может быть рекомендована система развитого директ-костинга. Для наиболее корректного внедрения на предприятии данной системы необходимо реализовывать её через программный продукт «1C: Предприятие 8 ERP Агропромышленный комплекс 2 » на 5 пользователей, стоимость реализации проекта составляет 43 тыс. руб. Данный продукт будет наиболее понятен руководству, поскольку предприятие ведёт свою бухгалтерию через «1С: Бухгалетрия 8».

При этом программа «1C: Предприятие 8 ERP Агропромышленный комплекс 2» представляет собой полноценную ЕRР-систему - организационную стратегию интеграции производства и операций, управления трудовыми ресурсами, финансового менеджмента и управления активами, ориентированную на непрерывную балансировку и оптимизацию ресурсов предприятия посредством специализированного интегрированного пакета прикладного программного обеспечения.

Заключение / Conclusion. Таким образом, рассматривая возможность внедрения сразу нескольких технологий, влияющих на эффективность производства зерна в СПК колхозе-племзаводе «Казьминском», можно составить следующую таблицу (таблица 4).

Таблица 4

Результативность внедрения мероприятий по повышению эффективности производства зерна в СПК колхозе-племзаводе «Казьминский»

\begin{tabular}{|l|c|c|c|c|}
\hline \multicolumn{1}{|c|}{ Показатели } & До внедрения мер & $\begin{array}{c}\text { Технико- } \\
\text { технологическе }\end{array}$ & $\begin{array}{c}\text { Организационно- } \\
\text { экономические }\end{array}$ & Отклонение (+/-) \\
\hline Урожайность, ц & 75 & 87 & 75 & 12 \\
\hline Объём производства, ц & 1134066 & 1533257 & 1134066 & 399191 \\
\hline Объём реализации, ц & 1174130 & 1521673 & 1291543 & 464956 \\
\hline Себестоимость 1 ц зерна, руб. & 648 & 627 & 643 & -26 \\
\hline Цена реализации 1 ц зерна, руб. & 881 & 899 & 890 & 27 \\
\hline Выручка, тыс. руб. & 1034408 & 1364856 & 1149473 & 445513 \\
\hline Затраты на внедрение, тыс. руб. & - & 103700 & 43 & -103743 \\
\hline Прибыль, тыс. руб. & 206067 & 381042 & 247269 & 216177 \\
\hline
\end{tabular}

Анализируя данные таблицы 4, можно говорить о том, что наибольший эффект увеличения выручки достигается при внедрении технико-технологических мероприятий. Они влияют на урожайность, которая возрастает на 12 ц/га. При этом объём производства увеличивается на $35 \%$, снижая себестоимость 1 ц зерна на $4 \%$. Такие мероприятия позволят организации увеличить цену реализации за счёт роста качества.

Затраты на внедрение новой техники и удобрений составляют 103700 тыс. руб. Все применяемые меры позволят увеличить урожайность зерновых в среднем на 12 ц с га, сократить их себестоимость на $4 \%$, что выльется в увеличение выручки на $43 \%$ и, как следствие, прирост чистой прибыли на $70 \%$.

Подводя итог вышеизложенному, можно говорить о том, что внедрять лишь одну технологию не всегда эффективно. Многие методы могут дать очень высокие результаты лишь в совокупном использовании, например, внесение новых удобрений и использование более современной техники.

\section{ЛИТЕРАТУРА И ИНТЕРНЕТ-РЕСУРСЫ}

1. Булгакова Л. Н. Управление финансово-хозяйственной деятельностью предприятия: монография. 4-е изд. М.: Перспектива, 2015. С. 176.

2. Шаронова Е. В. Рынок зерна России: проблемы и перспективы // Два комсомольца. 2015. № 4. С. 29-32. 
3. Официальный сайт компании «Ростсельмаш» [Электронный pecypc]. URL: www.rostselmash.com (Дата обращения: 27.11.2018).

4. Официальный сайт СПК колхоз-племзавод «Казьминский» [Электронный ресурc]. URL: www. stavropol.ru/kazminskiy - (Дата обращения: 27.11.2018).

5. Официальный сайт группы компаний «ИНTAЛЕВ» [Электронный pecypc]. URL: www.intalev.ru (Дата обращения 19.09.2018).

6. Официальный сайт компании РИА Новости [Электронный ресурc]. URL: https://ria.ru/lenta/location Stavropolskijj_krajj - (Дата обращения 05.10.2018).

7. Официальный сайт социального проекта «Элита нации» [Электронный pecypc]. URL: www.elite-rf. $\mathrm{ru}$ - (Дата обращения 18.09.2018).

8. Свободная интернет энциклопедия [Электронный pecypc] - URL: https://ru.wikipedia.org/wiki/Контроллинг - (Дата обращения 05.10.2018).

\section{REFERENCES AND INTERNET RESOURCES}

1. Bulgakova L. N. Upravlenie finansovo-hozyajstvennoj deyatel'nost'yu predpriyatiya (Management of financial and economic activity of the enterprise): monografiya. 4-e izd. M.: Perspektiva, 2015. S. 176.

2. SHaronova E. V. Rynok zerna Rossii: problemy i perspektivy (The grain market of Russia: problems and prospects) // Dva komsomol'ca. 2015. № 4. S. 29-32.

3. Oficial'nyj sajt kompanii «Rostsel'mash» (The official site of the Rostselmash company) [Electronic resource]. URL: www.rostselmash.com (appeal date: 11/27/2018).

4. Oficial'nyj sajt SPK kolhoz-plemzavod «Kaz'minskij» (Official site SEC kolkhoz-tribal plant «Kazminsky») [Electronic resource]. URL: www.stavropol.ru/kazminskiy (circulation date: 11/27/2018).

5. Oficial'nyj sajt gruppy kompanij «INTALEV» (Official site of the INTALEV group of companies) [Electronic resource]. URL: www.intalev.r u (Appeal date 19.09.2018).

6. Oficial'nyj sajt kompanii RIA Novosti (Official site of the company RIA Novosti) [Electronic resource]. URL: https://ria.ru/lenta/location_Stavropolskijj_krajj - (Date of circulation 05.10.2018).

7. Oficial'nyj sajt social'nogo proekta «EHlita nacii» (The official website of the social project «Elite of the Nation») [Electronic resource]. URL: www.elite-rf.ru - (Date of appeal 09/18/2018).

8. Svobodnaya internet ehnciklopediya (Free Internet Encyclopedia) [Electronic resource]. URL: https:// ru.wikipedia.org/wiki/Controlling - (Access date 05.10.2018)

\section{СВЕДЕНИЯ ОБ АВТОРАХ}

Косторный Игорь Юрьевич, студент 1 курса магистратуры, направления международного менеджмента, Северо-Кавказский федеральный университет. E-mail: gosha.kostorniy@yandex.ru

Лепяхова Елена Николаевиа, кандидат социологических наук, доцент, доцент кафедры менеджмента, Северо-Кавказский федеральный университет. E-mail: lika64@list.ru

\section{INFORMATION ABOUT THE AUTHORS}

Igor Kostornyy, a student of the 1st year of the master's program, international management, North Caucasus Federal University. E-mail: gosha.kostorniy ayandex.ru

Elena Lepyakhova, Candidate of Sociological Sciences, Associate professor, Associate professor of the department of management. North Caucasus Federal University. E-mail: lika64@1ist.ru 